\title{
Powerful Little Numbers: How Bandwagon Cues Influence Consumer Purchase Intention for Online Content
}

\author{
Pengya Ai \\ Shanghai Jiao Tong University, China \\ Email: aipengya1997@163.com \\ Wu Li* \\ *Corresponding author \\ Shanghai Jiao Tong University, China \\ Email: liw555@sjtu.edu.cn
}

Annette Ding

Shanghai Jiao Tong University, China

Email: annette_ding@126.com

\begin{abstract}
In the last few years more and more Chinese Internet users are turning to paid digital content for educational and professional guidance. Drawing on the MAIN model and the social impact theory, this study examines how bandwagon cues of the content product and professional backgrounds of the content provider impact consumer trust and purchase intention. In a $2 \times 2$ between-subject factorial design, participants viewed a introduction interface of a online content product depicting high and low levels of bandwagon cue and source expertise. Our study suggests that bandwagon cues indirectly affect consumer purchase intention, mediated by consumer trust, and that the effect is contingent upon the content provider having a high level of expertise. Managerial implications are also provided based on the empirical results.
\end{abstract}

Key words: Bandwagon cues, Pay for online content, Purchase intention, Source expertise, Trust

\section{Introduction}

In the age of social commerce, social design features have become commonplace amongst websites and applications, where the attitudes and behaviors of other users can be perceived via cues they leave behind (Huang \& Benyoucef, 2013). Many of these cues come in the form of simple numerical indicators, such as the number of views, comments, likes or dislikes. According to the Sunder's MAIN model (2008), cues that indicate collective approval from other users trigger the bandwagon heuristic, which can lead to perceptions of higher credibility or quality. Thus, this study will refer to the positive cues generated from the new design features 
of social commerce as bandwagon cues. Social Impact Theory (SIT) posits that when other people are the source and the individual is the impacted tartget, the impact should be a multiplication of the strength, immediacy, and number of other people. Specficially, the source can be the real, implied, or imagined presence or actions of other individuals (Latané, 1981). Strength, immediacy, and number have been examined as independent variables, contributing to the understanding social influence in past studies (Miller \& Brunner, 2008). Number refers to the number of sources of impact relative to targets of impact, thereby bandwagon cues can be seen as representative of the number dimension in SIT(Latané, 1981).

The practice of paid content has been emerging in various platforms, such as online news, music streaming, audiobooks, etc. In China, there has been a surge in the paid digital content market with many applications developing and adding paid content or services. In 2016, paid digital content platforms were estimated to reach an economy scale of 30 million CNY by 2017 (Cai et.al., 2018). The rise in paid digital content has mainly taken place on knowledge seeking platforms such as online radio APP and question-and-answer platforms (e.g Zhihu, Igetget, Ximalaya). Thus, for clarity, this study will refer this type of digital content platforms as paid knowledge platforms. Most of these paid knowledge platforms follow the same mode as other online paid content and services, where one cannot access the product beforehand and must pay ahead of consuming the content. Paid knowledge platforms encourage professionals to provide high quality content to their customers, because what distinguishs them from other paid digital content services is their professionalism and profundity (Zhang et.al., 2019).

Though various theories and concepts have been adopted to understand consumer purchase intention or willingness to pay (WTP) for online content, such as the Theory of Planned Behavior (TPB), free mentality, media use and demographic variables, etc. (Dou, 2004; Chyi, 2005; Dutta, 2012; Lin et.al., 2013), few have considered how bandwagon cues influence user willingness to pay for online content.

Before payment is paid, users cannot gain access to paid digital content and exist in a state of information asymmetry in relation to the content provider. Signaling theory posits that the party lacking information will use related signals to speculate (Connelly, 2011). Based on this theory, various cues can be employed by consumers to infer information about the product and its providers, including bandwagon cues and source expertise, which in turn impact their decision to purchase. The MAIN model also suggests that bandwagon cues and source expertise demonstrated in the online context affect consumer perception and decision-making (Sundar, 2008). Regarding the professionalism and profundity of paid knowledge platforms, we posit source expertise to be more important than in the case of regular paid content. Therefore, source expertise may also affect consumer perception and behavior, and may moderate the effect of bandwagon cues on purchase intention.

Since content providers are presented as single individuals and many of them are celebrities in the real and/or virtual world, they play a dual role on paid knowledge platforms as both content providers and promoters. Considering the significant role played by content providers on paid knowledge platforms, it is necessary to consider consumer trust towards them. How trustworthy 
a consumer perceives an seller to be has been shown to impact consumer purchase intention and behavior (Hong \& Cha, 2013; Lu et.al., 2010). Similar to other e-commerce products, particularly experience products, it can be difficult for user to predict the quality of paid digital content as little product information can be provided prior to payment. Thus, trust becomes a significant factor in the success of online purchases (Hong, 2015). Consequently, we propose consumer trust to be a mediating variable between bandwagon cues and purchase intention.

In conclusion, the goal of this study is to empirically examine how bandwagon cues affect user willingness to pay for online content. Specifically, three questions are raised: (1) How do bandwagon cues affect a consumer trust and purchase intention? (2) Will trust acts a mediating variable between bandwagon cues and purchase intention? (3) Will source expertise moderate the effect of bandwagon cues on trust and purchase intention?

\section{Literature review}

\subsection{Bandwagon cues}

According to the MAIN model, bandwagon cues imply "collective endorsement and popularity of the underlying content" (Sundar, 2008). The bandwagon effect has been widely supported by previous studies across various contexts, such as sense of community (Kim, 2011; Kim, 2014); the perceived importance others assign to the climate change issue (Spartz et.al., 2017); the perceived popularity of Instagram influencers and their likability (De Vairman et.al., 2017); news credibility and issue importance (Waddell, 2018); eating intention, envy, and para-social interaction (Jin, 2018); attitude towards a company and its CSR campaign (Kim \& Xu, 2019). Generally, a high bandwagon cue leads to higher perceived popularity (De Vairman et.al., 2017), higher perceived credibility (Waddell, 2018), and a more positive attitude (Kim \& Xu, 2019). The advent of social media and Web 2.0 technologies have made it easy to provide and collect socially rich information. Users merely have to click "like" or "thumbs up" to express their positive attitude towards the content. Thus, bandwagon cues act as a representation of popularity and the collective endorsement of the paid content, and in turn the content provider. When information is lacking, users will refer to those signals to speculate the ability of the provider and content quality. Examining bandwagon cues (e.g. number of users show interest to a product, number of shares, number of actual purchases, etc.) as a representation of social presence, Lu et.al. (2016) found that they have a positive effect on consumer trust towards the online seller. Based on the above overview, the first hypothesis is proposed:

\section{H1: Higher levels of the bandwagon cue will lead to positively affects consumer trust towards content providers.}

As mentioned before, a higher bandwagon cue shows that more people endorsed the content. It is reasonable to suppose that a higher bandwagon cue is more likely to nudge users to form a positive impression and in turn make a decision to purchase. Past studies have demonstrated the positive relationship between bandwagon cues and user purchase intention. Specifically, an 
experiment conducted by Coulter \& Roggeveen (2012) on group buying websites showed that the number of buyers have a positive effect on a consumer's purchase decision. Applying a heuristic-systematic model, Zhang et.al. (2014) set the perceived quantity of reviews as a heuristic factor and posited that consumers recognize the popularity of products on the websites by consulting such numerical information. Their survey data demonstrated that the perceived quantity of reviews has a significant positive impact on user purchase intention. In addition, based on data crawled from Zhihu.com, a popular paid question-and-answer platform in China, Zhao et.al. (2018) found that bandwagon cues positively predict a user's decision to purchase online content. Therefore, this study proposes a second hypothesis:

\section{H2: Bandwagon cues positively affects users' online content purchase intention.}

\subsection{Trust}

As a social phenomenon, trust has been studied across various disciplines including social psychology, sociology, economics, and marketing (Doney et.al., 1997). As mentioned above, paid digital content exist in an environment of information asymmetry, where the risk for opportunistic behavior on the seller's side increases. Customer may suspect the content provider's motives while recognizing that they do not have the capacity to detect deception, which in turn can impede their purchase intention. Therefore, the importance of trust emerges (Singh \& Sirdeshmukh, 2000).

Trust is a psychological state comprising of the intent to accept vulnerability based on the positive expectations of another's intentions, or a willingness to rely on exchange partners (Singh \& Sirdeshmukh, 2000; Ganesan, 1994) Perceived trust is defined as a set of beliefs about the trustworthiness of a content provider (Kim et.al., 2012). Trust has been widely demonstrated to have a positive impact on purchase intention. For example, based on survey data, Hsin Chang \& Wen Chen (2008) revealed trust towards the online retailor positively influences online purchase intention. Hong (2015) found that the more customers perceived an e-tailor to be trustworthy, the more likely they will buy from that e-tailor. Pappas (2016) also revealed customer trust towards a Web-vendor has a positive impact on their intent to purchase. Thus, it can be assumed that if consumer trust towards content provider is higher, the intention to pay for online content would be higher.

Also taking into account the literature review for the first hypothesis, this study puts forth the hypothesis:

H3: Trust positively affects users' online content pay intenton, and mediates the effect of bandwagon cues to users' online content purchase intention.

\subsection{The moderating effect of source expertise}

Source characteristics are an important factor affecting consumer trust, amongst which expertise is commonly recognized as one of the most crucial (Pornpitakpan, 2004; Amos, et.al., 
2008). In this study, source expertise is conceptualized as (the content provider) having skills or knowledge obtained from formal training in a specific field. Previous studies have found that a content provider's expertise has a significantly positive influence on consumer trust (Kim \& Ahn, 2007; Wood et.al., 2008), consumer trust towards the promoter (Wood et.al., 2008), evaluation of brand extensions (Vanhocker, 2007), purchase intention for utilitarian products (Wen, et.al., 2009), etc. Therefore, this study posits that in the context of paid knowledge content, the expertise of the content provider may influence the consumer's trust towards them and the consumer's intention to purchase online content.

Given the potential effect source characteristics have on trust and purchase intention, they also may moderate the effect of bandwagon cues. The degree to which a user will depend on bandwagon cues may vary across different source characteristics. Previous findings have demonstrated the interaction effect between sources characteristics and bandwagon cues on user perception and behavior intention, though the findings are not consistent. For example, Sunder et al. (2007) examined the interaction effect of cues on perceived message credibility, news worthiness, and likelihood of clicking on the news leads. Their results showed a source primacy effect where bandwagon cues matter only when source credibility is low, and a cuecumulation effect, indiciating bandwagon cues boost positive perception when perceived source credibility is low. In their study on tweets, Lin et al. (2014) found bandwagon cues and source identity to have a cue-cumulative effect, that is, the co-presence of more cues enhance the positive effect of perceived source credibility in tweets. Chung (2017) further concluded that bandwagon cues play a more important role when source credibility is low.

However, some studies suggest the interaction of bandwagon cues and source characteristics relies on context. For example, Go (2014) revealed a significant two-way interaction effect between expertise and bandwagon cues on perceived credibility, suggesting a positively combined effect of the two variables. Further investigation found that the interaction effect relies on group identity. When examining the effect of social media cues on the publics' response to corporate social responsibility (CSR), Kim \& Xu (2019) did not find any interaction effect between message source characteristic and bandwagon cue on attitudes toward the company, attitude towards the CSR campaign, or intention to engage in WOM about the campaign.

Therefore, there is not enough evidence to draw a clear conclusion on the interaction effect of bandwagon cues and source characteristics. Moreover, in all the studies mentioned above, the findings were all in the context of free online content. However, the distinction between paid online content and free online content should be taken into consideration when exploring the interaction effect on purchase intention towards online content. The most pressing difference is that the perception of economic costs will change how people process the information. Past research has shown that, no matter how small the economic cost, "free" makes a distinct difference in people's minds (Ariely et.al., 2009; Shampanier et.al., 2007). Regarding paying for online content, the "free mentality" plays a significant role in relation to purchase intention in that there is a widely held expectation that online content be free of charge (Chyi, 2005; Lin 
et.al., 2013). Therefore, this study intends to provide an exact examination of the interaction effect between bandwagon cue and expertise:

RQ1: Will expertise moderates the effect of bandwagon cues on user online content purchase intention?



Figure 1. Conceptual framework proposed.

\section{Method}

\subsection{Participants}

This experiment was conducted during the month of April in 2019 at two universities in Shanghai, China. In order to avoid the potential impact of past user experience, we required participants who had never paid for online content. A total of 151 students completed the study and were offered a gel pen as a gift after the experiment. Out of the 151 participants, 80 were female (53.0\%), 71 of them were male (47.0\%); 91 students majored in science and engineering $(60.3 \%), 60$ majored in the humanities \& social sciences; 69 were junior undergraduates (45.7\%), 40 were senior undergraduates (26.5\%), and 42 were graduate students $(27.8 \%)$. As for disposable monthly income, 28 participants reported lower than 1000 RMB yuan (18.5\%), 41 between 1001-1500 RMB yuan (27.2\%), 35 between 1501-2000 RMB yuan (23.3\%), and 47 more than 2000 RMB yuan $(31.1 \%)$.

\subsection{Design and procedure}

The study employed a 2 (bandwagon cue: high vs. low) $\times 2$ (source expertise: high vs. low) between-subject factorial design. The participants were randomly assigned to one of four stimuli conditions with different levels of bandwagon cue and source expertise. The four stimuli conditions were (1)high bandwagon cue \& high source expertise $(\mathrm{n}=41)$; (2) low bandwagon cue $\&$ high source expertise $(n=39)$; (3)high bandwagon cue $\&$ low source expertise $(n=36)$; (4) low bandwagon cue \& low source expertise $(n=35)$. Chi-squared test showed there was no difference among 4 groups in terms of gender $\left(\chi^{2}=2.875, d f=3, p=0.411\right)$, grade $\left(\chi^{2}=\right.$ 9.565, $d f=6, p=0.411)$, major $\left(\chi^{2}=0.692, d f=3, p=0.875\right)$, and disposable monthly income $\left(\chi^{2}=6.588, d f=9, p=0.680\right)$. 
After viewing the screenshots, participants were asked to report their perceived popularity of the online content, perceived expertise of the content provider, involvement with the content, trust towards the content provider, purchase intention towards the content, as well as demographic information. Finally, they were thanked and debriefed.

\subsection{Stimuli}

As mentioned in the section of introduction, online paid content platforms have been rapidly developed and popular with the Chinese Internet user since 2016. In the present study, online audio guides for books, one of the most popular types of online paid contents, was choosen as the stimuli material. Compared with other types such as audio courses, the product of online audio guides for books is not serial-based, and a single episode usually last around 30 minnutes, which enables participants to finish the complete produt trail at the laboratory scenario. All the information including book title presented on the stimuli material was fabricated in order to avoid instances where the participants might have existing impressions of a real book.

Bandwagon cue in this study was manipulated by varying the number of others' liking, namely the number of consumers interested in the online content. Participants in the high bandwagon condition were told that there were 1834 consumers who liked the content, whereas participants in the low bandwagon condition were told that only 3 consumers liked the content. Source expertise was manipulated by giving the different labels to the content provider to display their different levels of expertise. Considering the fact that the book topic we chose for the stimuli is on psychological well-being and self-control, the content provider was labeled as "a $\mathrm{PhD}$ in psychology" together with "a content provider for the platform" for the high-expertise condition. Meanwile, for the low-expertise condition, the content provider was only given the label as "a content provider for the platform".

\subsection{Measures}

The dependent variable is consumer purchase intention towards online content. Measurement items for this construct were adapted from Dodds et al. (1991), including "My willingness to pay for the content is high", "The probability that I would consider buying the content is high", and "The likelihood of purchasing this content is high". Internal consistency of the measurement was verified with Cronbach's $\alpha=0.975$, far exceeding the 0.70 threshold.

The measurement of consumer trust towards the content provider consisted of two items, which were adapted from Kim et al. (2012). The two items were "The content provider is trustworthy" and "The content provider is capable of doing his/her job" repectively. The internal consistency of this construct was also excellent (Cronbach's $\alpha=0.921$ ).

Except for basic demographic variables including college sutdents' gender, major, grade and disposable mothly income, involvement was also considered as an extra control variable. Since the content topic was the same for all participants, it was not warranted that every participant would be interested in the subject, which may impact user perception and intention, the variable 
of involment needs to be taken into consideration as well. The measurement items were adapted from Holzwarth et al. (2006), which included: "The content is relevant for me", "The content is important for me", "I'm interested in the content" (Cronbach's $\alpha=0.931)$.

All items above were anchored on a seven-point Likert scale ranging from 1 (strongly disagree) to 7 (strongly agree).

\section{Results}

\subsection{Manipulation check}

Participants were given four questions to assess whether they correctly recognized bandwagon cue and source expertise in evaluating the online content. To be specific, the participants were asked to indicate how popular the content was ("The content is popular", "There are lots of people interested in the content", Cronbach's $\alpha=0.898$ ) and how much of an expert they perceived the content provider to be ("This content provider is expertise in psychology", "This content provider has lots of knowledge in psychology", Cronbach's $\alpha=0.935$ ).

The manipulation check was successful across the variables of bandwagon cue and source expertise. Participants who were exposed to the stimuli with high bandwagon cue perceived the content to be significantly more popular than those who received the stimuli with low bandwagon cue ( $M_{\text {high bandwagon cue }}=4.071, S D=1.197 ; M_{\text {low bandwagon cue }}=$ $3.682, S D=1.167 ; t(149)=2.022, p=0.045)$.In the same vein, those who were exposed to the content provider with the lable "a $\mathrm{PhD}$ in psychology" perceived him/her to have significantly higher expertise ( $M_{\text {high source expertise }}=4.981, S D=$ $\left.1.170 ; M_{\text {low source expertise }}=4.113, S D=1.138 ; t(149)=4.612, p<0.001\right)$.

\subsection{Moderated mediating effect}

The bootstrapping approach does not impose an assumption of normality, thereby providing more accurate confidence intervals than alternative methods for assessing mediation effects and has received much attention recently (Cheung \& Lau, 2008). Thus, we applied this approach to empirically test our coceputal model. PROCESS SPSS macro (Hayes, 2012) was employed to qualify the moderated mediation model, with bandwagon cue as the independent variable, consumer trust as the mediator, purchase intention as dependent variable, and source expert as the moderator of the effect of bandwagon cue on consumer trust. Before conducting the data analysis, the experimental treatment of bandwagon cue was coded as one dummy variable $(0=$ low bandwagon cue, 1 = high bandwagon cue), and source expertise was coded as another dummy variable $(0=$ low source expertise, $1=$ high source expertise $)$.

Firstly, providing support for this moderated mediation process model, the interaction of the two variables (bandwagon cue $\times$ source expertise) had a significant impact on consumer trust (mediator) with a 0.05 significance level $(\beta=0.5652, p=0.0472, C I=[0.0071,1.1233]$ ). 
In turn, consumer trust significantly predicted purchase intention $(\beta=0.4252, p<$ $0.001, C I=[0.2227,0.6276])$. The interaction of bandwagon cue and source expertise was not a significant predictor of purchase intention after controlling for the mediator consumer trust $(\beta=0.0008, p=0.9981, C I=[-0.6899,0.6916])$, which indicates that consumer trust fully mediates the interaction. The control variables, involvement and demographic factors such as gener, amjor and grade, are included in the model (see Table 1, Regression analysis).

Table 1. Regression analysis.

\begin{tabular}{|c|c|c|c|c|c|c|c|c|}
\hline \multirow[t]{2}{*}{ dependent variable } & \multicolumn{4}{|c|}{$\begin{array}{c}\text { Model } 1 \\
\text { consumer trust }\end{array}$} & \multicolumn{4}{|c|}{$\begin{array}{c}\text { Model } 2 \\
\text { purchase intention }\end{array}$} \\
\hline & coff. & $\mathrm{p}$ & LLCI & ULCI & coff. & $\mathrm{p}$ & LLCI & ULCI \\
\hline \multicolumn{9}{|l|}{ independent variables } \\
\hline bandwagon cue & 0.0374 & 0.8554 & -0.3675 & 0.4423 & -0.1249 & 0.6183 & -0.6192 & 0.3695 \\
\hline source expertise & 0.1792 & 0.3733 & -0.2174 & 0.5757 & -0.3033 & 0.2187 & -0.7887 & 0.1820 \\
\hline bandwagon cue $\times$ source expertise & 0.5652 & 0.0472 & 0.0071 & 1.1233 & 0.0008 & 0.9981 & -0.6899 & 0.6916 \\
\hline consumer trust & & & & & 0.4252 & 0.0001 & 0.2227 & 0.6276 \\
\hline \multicolumn{9}{|l|}{ control variables } \\
\hline involvement & 0.5805 & 0.0000 & 0.4683 & 0.6927 & 0.4584 & 0.0000 & 0.2779 & 0.6390 \\
\hline gender & -0.0421 & 0.7734 & -0.3303 & 0.2461 & -0.1609 & 0.3676 & -0.5128 & 0.1910 \\
\hline major & -0.1005 & 0.4977 & -0.3926 & 0.1917 & 0.0505 & 0.7801 & -0.3066 & 0.4077 \\
\hline grade & 0.0090 & 0.8354 & -0.0767 & 0.0948 & 0.0648 & 0.2235 & -0.0400 & 0.1695 \\
\hline disposable monthly income & 0.0646 & 0.2624 & -0.0489 & 0.1780 & -0.0397 & 0.5732 & -0.1788 & 0.0993 \\
\hline constant & 1.4096 & 0.0002 & 0.6754 & 2.1437 & -0.3528 & 0.4595 & -1.2932 & 0.5876 \\
\hline \multicolumn{9}{|l|}{ model fit } \\
\hline$R$ & \multicolumn{4}{|c|}{0.6912} & \multicolumn{4}{|c|}{0.6904} \\
\hline$R^{2}$ & \multicolumn{4}{|c|}{0.4778} & \multicolumn{4}{|c|}{0.4766} \\
\hline$F$ & \multicolumn{4}{|c|}{$16.2415^{* * *}$} & \multicolumn{4}{|c|}{$14.2659^{* * *}$} \\
\hline
\end{tabular}

Secondly, the significance of the direct and indirect effect of consumer trust on purchase intention were examined across each level of source expertise with bootstrapped standard errors and $95 \%$ confidence intervals (CIs). No direct effect of consumer trust has been found no matter when source expertise is high $(C I=[-0.6192,0.3695])$ or low $(C I=[-0.6060,0.3580])$, for the $95 \% \mathrm{CI}$ includes 0 at both conditions (Table 2). As presented in Table 3, the indirect effect of consumer trust was significant in the condition of high source expertise condition but not in that of low source expertise. To be specific, when source expertise is high, the result revealed a significantly positive indirect effect $(C I=[0.1101,0.4825])$. However, when source expertise is low, the limit of the 95\% CI includes $0(C I=[-0.1466,0.2068])$, suggesting the result is not statistically significant.

Table 2. Conditional direct effect

\begin{tabular}{lllll}
\hline source expertise & Effect & SE & LLCI & ULCI \\
\hline 0 (low source expertise) & -0.1249 & 0.2500 & -0.6192 & 0.3695
\end{tabular}


\begin{tabular}{lllll}
1 (high source expertise) & -0.1240 & 0.2438 & -0.6060 & 0.3580 \\
\hline
\end{tabular}

Table 3. Conditional indirect effect

\begin{tabular}{llllll}
\hline indirect effect & source expertise & Effect & Boot SE & BootLLCI & BootULCI \\
\hline consumer trust & 0 (low) & 0.0159 & 0.0904 & -0.1466 & 0.2068 \\
consumer trust & 1 (high) & 0.2562 & 0.0904 & 0.1101 & 0.4825 \\
\hline
\end{tabular}

Note. Conditional indirect effects are based on 2000 bootstrap samples.

\section{Discussion}

Taken altogether, the results indicate bandwagon cues do have an effect on a user willingness to pay for online content, in line with with past studies. However, the effect is conditional. Bandwagon cues do not have a direct effect on purchase intention and consumer trust fully mediates the impact of bandwagon cues on purchase intention. Moreover, the indirect effect exists only when source expertise is high. That is, users will first figure out whether the content provider is of high expertise or not. If the content provider is perceived to have a high level of expertise, a higher bandwagon cue will elevate a user's trust towards the content provider, leading to a higher purchase intention towards the online content. If content provider is of low expertise, a higher bandwagon cue will no longer have an effect on consumer trust, let alone the user's intent to purchase online content. The results show that when online content is not free and are of a professional nature, users will become extremely picky. Specifically, users will first weigh the content provider's expertise, and then refer to other users' opinion to inform their trust towards the content provider, further influencing their purchase intention.

This study extends current online cues research into the paid online content market, theoretically contributing to both online cues research and online content purchase intention research. Our findings are partly aligned with cue-cumulation effect research, but contrary to that of source primacy effect (Sundar et.al., 2007). Given the various findings regarding the effect of online cues, it can be suggested that the effect of online cues rely highly on context. This context reliance phenomena may be explained by uses and gratifications theory (U\&G) and the heuristics-systematic model (HSM). U\&G posits different users choose different media to fulfill different needs according to their specific individual needs and media attributes (Katz et.al., 1973). Unlike the majority of online content consumption examined in previous studies, the content in this study is not free. Given the same content, the motivation levels of users who pay for the content should be higher than those who get the content for free. HSM implies that people choose different information processing methods to process the same information according to their own characteristics (e.g. motivation): higher levels of motivation are more likely to elicit systematic processing, while lower levels of motivation more likely lead to heuristic processing (Chen et.al., 1999). As for paid digital content platform, users tend towards systematic processing; they form their judgements through an in-depth analysis of the information on the interface (Chaiken, 1980). In that context, a single bandwagon cue is not enough to form a high leve of trust and elicit intent to purchase. Whereas in past researches 
focusing on free online content, users are inclined to use heuristic processing; they will exert comparatively less effort to analyze information to form a judgement (Chaiken, 1980), and may rely on bandwagon cue to compensate for the lack of source credibility (Sundar et.al., 2007; Chung, 2017).

This study also has managerial implications for online content providers and online payment platforms. For online content providers, it's necessary to use appropriate kinds of publicity to express their professionalism and improve their expertise. At the same time, attempting to achieve a higher level of popularity is also needed. For example, content provicers can offer free probationary versions of their knowledge content or initially provide the content for free for a restricted period time to attract users, in order to accumulate enough likes to form a higher bandwagon cue. Online paid knowledge platforms should also focus on the expertise level of their content producers, whether it is by having stricter requirements for expertise when recruiting and hiring, or by working to improve the expertise of their current content providers. In the early development stage online content platforms in China, celebrities are often invited as content providers to attract users. The idea behind this strategy is to gain a high bandwagon cue early on during the initial release. However, according to our findings, this strategy may not be that effective in the long run unless the expertise of content providers is ensured as well. In addition, our regression analysis shows that user involvement with the content has a statistically significant impact on their trust and purchase intention, which suggests in addition to improving the expertise of content providers, matching content with users is an important aspect for platforms and providers to consider.

However, the present study is not without its limitations. Firstly, this study chose to specifically examine paid knowledge platforms, but digital paid content platforms are not limited to such types of content. Thus, the results of this study cannot be generalized to other types of paid online content, such as music, news, etc. In future studies, different types of paid online content should be considered to establish further generalizability. Secondly, the participants are all college students, though students are the majority of potential users of online content platforms, there may still remain some gaps between college students and working professionals that may affect the results. In future research, the range of participants recruited should be expanded. Finally, we only examined the effect of bandwagon cues on consumer trust and purchase intention, however bandwagon cues may impact other variables as well. Thereby, more types of dependent variables can be included to explore the wider range of possibilities that bandwagon cues can yield.

Acknowledgements We are incredibly grateful to Chinese Institute for Quality Research in Shanghai Jiao Tong University (2018CIQ001) for financial support. 


\section{Reference}

Amos, C., Holmes, G., \& Strutton, D. (2008). Exploring the relationship between celebrity endorser effects and advertising effectiveness: A quantitative synthesis of effect size. International journal of advertising, 27(2), 209-234.

Ariely, D., Bracha, A., \& Meier, S. (2009). Doing good or doing well? Image motivation and monetary incentives in behaving prosocially. American Economic Review, 99(1), 544-55.

Cai, S., Luo, Q. F., Fu, X., \& Ding, G. (2018). Paying for Knowledge: Why People Paying for Live Broadcasts in Online Knowledge Sharing Community?. In PACIS (p. 286).

Chaiken, S. (1980). Heuristic versus systematic information processing and the use of source versus message cues in persuasion. Journal of personality and social psychology, 39(5), 752.

Chen, S., Duckworth, K., \& Chaiken, S. (1999). Motivated heuristic and systematic processing. Psychological Inquiry, 10(1), 44-49.

Cheung, G. W., \& Lau, R. S. (2008). Testing mediation and suppression effects of latent variables: Bootstrapping with structural equation models. Organizational research methods, 11(2), 296-325.

Chung, M. (2017). Not just numbers: The role of social media metrics in online news evaluations. Computers in Human Behavior, 75, 949-957.

Chyi, H. I. (2005). Willingness to pay for online news: An empirical study on the viability of the subscription model. Journal of Media Economics, 18(2), 131-142.

Connelly, B. L., Certo, S. T., Ireland, R. D., \& Reutzel, C. R. (2011). Signaling theory: A review and assessment. Journal of management, 37(1), 39-67.

Coulter, K. S., \& Roggeveen, A. (2012). Deal or no deal? How number of buyers, purchase limit, and time-toexpiration impact purchase decisions on group buying websites. Journal of Research in Interactive Marketing, $6(2), 78-95$.

De Veirman, M., Cauberghe, V., \& Hudders, L. (2017). Marketing through Instagram influencers: the impact of number of followers and product divergence on brand attitude. International Journal of Advertising, 36(5), 798-828.

Dodds, W. B., Monroe, K. B., \& Grewal, D. (1991). Effects of price, brand, and store information on buyers' product evaluations. Journal of marketing research, 28(3), 307-319.

Doney, P. M., \& Cannon, J. P. (1997). An Examination of the Nature of Trust in Buyer-Seller Relationships. The Journal of Marketing, 35-51. 
Dou, W. (2004). Will internet users pay for online content?. Journal of Advertising Research, 44(4), 349-359.

Dutta, S. (2012). Analyzing consumer intention to pay for online content: A systematic approach. Journal of Theoretical and Applied Information Technology, 31(1), 89-102.

Ganesan, S. (1994). Determinants of long-term orientation in buyer-seller relationships. Journal of Marketing, 58(2), $1-19$

Go, E., Jung, E. H., \& Wu, M. (2014). The effects of source cues on online news perception. Computers in Human Behavior, 38, 358-367.

Hayes, A. F. (2012). PROCESS: A versatile computational tool for observed variable mediation, moderation, and conditional process modeling.

Holzwarth, M., Janiszewski, C., \& Neumann, M. M. (2006). The influence of avatars on online consumer shopping behavior. Journal of marketing, 70(4), 19-36.

Hong, I. B. (2015). Understanding the consumer's online merchant selection process: The roles of product involvement, perceived risk, and trust expectation. International Journal of Information Management, 35(3), 322-336.

Hong, I. B. (2015). Understanding the consumer's online merchant selection process: The roles of product involvement, perceived risk, and trust expectation. International Journal of Information Management, 35(3), 322-336.

Hong, I. B., \& Cha, H. S. (2013). The mediating role of consumer trust in an online merchant in predicting purchase intention. International Journal of Information Management, 33(6), 927-939.

Hsin Chang, H., \& Wen Chen, S. (2008). The impact of online store environment cues on purchase intention: Trust and perceived risk as a mediator. Online information review, 32(6), 818-841.

Huang, Z., \& Benyoucef, M. (2013). From e-commerce to social commerce: a close look at design features. Electronic Commerce Research and Applications, 12(4), 246-259

Jin, S. V. (2018). Interactive effects of Instagram Foodies' Hashtagged\# Foodporn and peer Users' eating disorder on eating intention, envy, Parasocial interaction, and online friendship. Cyberpsychology, Behavior, and Social Networking, 21(3), 157-167.

Katz, E., Haas, H., \& Gurevitch, M. (1973). On the use of the mass media for important things. American sociological review, 164-181.

Kim, M. S., \& Ahn, J. H. (2007). Management of trust in the e-marketplace: the role of the buyer's experience in building trust. Journal of Information Technology, 22(2), 119-132. 
Kim, H. S., \& Sundar, S. S. (2011, May). Using interface cues in online health community boards to change impressions and encourage user contribution. In Proceedings of the SIGCHI Conference on Human Factors in Computing Systems (pp. 599-608). ACM.

Kim, H. S., \& Sundar, S. S. (2014). Can online buddies and bandwagon cues enhance user participation in online health communities?. Computers in Human Behavior, 37, 319-333.

Kim, H. W., Xu, Y., \& Gupta, S. (2012). Which is more important in Internet shopping, perceived price or trust?. Electronic Commerce Research and Applications, 11(3), 241-252.

Kim, H., \& Xu, H. (2019). Exploring the effects of social media features on the publics' responses to decreased usage CSR messages. Corporate Communications: An International Journal, 24(2), 287-302.

Latané, B. (1981). The psychology of social impact. American psychologist, 36(4), 343.

Lin, T. C., Hsu, J. S. C., \& Chen, H. C. (2013). Customer willingness to pay for online music: The role of free mentality. Journal of Electronic Commerce Research, 14(4).

Lin, X., Spence, P. R., \& Lachlan, K. A. (2016). Social media and credibility indicators: The effect of influence cues. Computers in Human Behavior, 63, 264-271.

Lu, B., Fan, W., \& Zhou, M. (2016). Social presence, trust, and social commerce purchase intention: An empirical research. Computers in Human Behavior, 56, 225-237.

Lu, Y., Zhao, L., \& Wang, B. (2010). From virtual community members to C2C e-commerce buyers: Trust in virtual communities and its effect on consumers' purchase intention. Electronic Commerce Research and Applications, 9(4), 346-360.

Miller, M. D., \& Brunner, C. C. (2008). Social impact in technologically-mediated communication: An examination of online influence. Computers in Human Behavior, 24(6), 2972-2991.

Pappas, N. (2016). Marketing strategies, perceived risks, and consumer trust in online buying behaviour. Journal of Retailing and Consumer Services, 29, 92-103.

Pornpitakpan, C. (2004). The persuasiveness of source credibility: A critical review of five decades' evidence. Journal of applied social psychology, 34(2), 243-281.

Shampanier, K., Mazar, N., \& Ariely, D. (2007). Zero as a special price: The true value of free products. Marketing science, 26(6), 742-757.

Singh, J., \& Sirdeshmukh, D. (2000). Agency and trust mechanisms in consumer satisfaction and loyalty judgements. Journal of the Academy of Marketing Science, 28(1), 150.

Spartz, J. T., Su, L. Y. F., Griffin, R., Brossard, D., \& Dunwoody, S. (2017). YouTube, social norms and perceived salience of climate change in the American mind. Environmental Communication, 11(1), 1-16. 
Sundar, S. S. (2008). The MAIN model: A heuristic approach to understanding technology effects on credibility. Digital media, youth, and credibility, 73100.

Sundar, S. S., Knobloch-Westerwick, S., \& Hastall, M. R. (2007). News cues: Information scent and cognitive heuristics. Journal of the American Society for Information Science and Technology, 58(3), 366-378.

Vanhonacker, W. R. (2007). Brand extension naming strategies: An exploratory study of the impact of brand traits. Marketing Letters, 18(1-2), 61-72.

Waddell, T. F. (2018). What does the crowd think? How online comments and popularity metrics affect news credibility and issue importance. New Media \& Society, 20(8), 3068-3083.

Wen, C., Tan, B. C., \& Chang, K. T. T. (2009). Advertising effectiveness on social network sites: an investigation of tie strength, endorser expertise and product type on consumer purchase intention. ICIS 2009 Proceedings, 151.

Wood, J. A., Boles, J. S., \& Babin, B. J. (2008). The formation of buyer's trust of the seller in an initial sales encounter. Journal of Marketing Theory and Practice, 16(1), 27-39.

Zhang, J., Zhang, J., \& Zhang, M. (2019). From free to paid: Customer expertise and customer satisfaction on knowledge payment platforms. Decision Support Systems, 113140.

Zhang, K. Z., Zhao, S. J., Cheung, C. M., \& Lee, M. K. (2014). Examining the influence of online reviews on consumers' decision-making: A heuristic-systematic model. Decision Support Systems, 67, 78-89.

Zhao, Y., Zhao, Y., Yuan, X., \& Zhou, R. (2018). How knowledge contributor characteristics and reputation affect user payment decision in paid Q\&A? An empirical analysis from the perspective of trust theory. Electronic Commerce Research and Applications, 31, 1-11. 